\begin{tabular}{lll}
\multicolumn{3}{l}{ Abstract G108(P) Table 1 } \\
\hline Number- & $\begin{array}{l}\text { Jan'13-Dec'13 } \\
\text { (1 year) }\end{array}$ & Mar'16-Feb'19 (After PNJ pathway) (3 years) \\
\hline Of referrals & 222 & $166(55 /$ year) \\
Attending clinic & 182 & 137 (46/year) \\
Investigated & 88 & $51(17 /$ year) \\
With pathological & 0 & 5 (1 biliary atresia, 2 G6PD deficiency, 1 congenital \\
cause & & hypothyroidism, 1 still under investigation) \\
\hline
\end{tabular}

Conclusion PNJ referrals declined by $75 \%$ following implementation of the pathway. Number of infants investigated reduced by $80 \%$; whilst still effectively and timely identifying serious pathology. It meant 167 less clinic appointments and 71 fewer infants investigated per annum.

Recommendation PNJ pathway improved service-efficiency whilst effectively identifying serious pathology. Most importantly, it is community-based, family-friendly and a safe approach to PNJ management. NICE should consider adopting this approach.

\section{G109(P) TRANSFORMING EDUCATION AND TRAINEE EXPERIENCE USING QUALITY IMPROVEMENT}

${ }^{1,2} \mathrm{H}$ Zhu, ${ }^{1,2} \mathrm{~N} \mathrm{Ng},{ }^{2} \mathrm{R}$ Tresman, ${ }^{1,2}{ }^{2} \mathrm{~S}$ Cooke, ${ }^{1,2} \mathrm{E}$ Routh, ${ }^{2} \mathrm{~A}$ Roberts, ${ }^{2} \mathrm{~J}$ Morris. ${ }^{1}$ Community Paediatrics, Evelina Children's Hospital, London, UK; ${ }^{2}$ General Paediatrics, Kingston Hospital, Kingston-Upon-Thames, UK

\subsection{6/archdischild-2020-rcpch.86}

Aims Problem statement: Paediatric trainees expressed dissatisfaction with local training on the GMC survey. This led to poor morale, trainees feeling disadvantaged and less equipped to provide excellent quality of care.

This project aimed to improve quality of paediatric training by promoting a supportive learning environment and proactively sharing learning experiences from July 2018 to August 2019.

Methods Our problem analysis involved the 2018 GMC survey and qualitative local questionnaires. We identified key areas for improvement; teaching attendance, rota design and use of feedback. Our process measures were evidence of shared learning and our outcome measures were trainee satisfaction in the 2019 GMC survey. Change ideas were implemented by a team of Education Champions comprising junior doctors and consultants. Education governance was improved by teamwork, transparency and shared consultant responses to all areas of trainee feedback. Protected teaching sessions and clinic opportunities were built into rotas, including monthly half-day education symposia for Registrars.

Results Learning points were discussed at Monday handovers, led by the night team and on-call consultant. PDSA cycles showed positive uptake on run charts, with a median of 3 learning points shared weekly on WhatsApp, sustained for 3 months through frequent reminders by champions. However, this dropped in number during holidays and increased locum cover.

Monthly education summaries sharing local learning were emailed, with excellent stakeholder feedback. These improved morale and engagement in teaching by celebrating the range of local and national training provided. Education whiteboards were used to educate on monthly topics, update trainees of upcoming educational opportunities, display quality improvement projects and share learning points.

The GMC Training Survey showed improvement in all areas and overall trainee satisfaction increased from $70 \%$ to $82 \%$ from 2018-2019. Improvements in local teaching (increased from 53\% to 68\%) and handover (65\% to $80 \%)$ were particularly encouraging.

Conclusion This project demonstrates how the model for improvement can be used to systematically improve education and trainee experience. Using multiple modes of communication for regular sharing of learning can embed education into a busy working day and improve trainee satisfaction. Ongoing PDSA cycles and champions are required to sustain further improvements in education and trainee experience.

\section{G110(P) KEEP CALM AND INTUBATE (USING CHECKLISTS ON THE NEONATAL UNIT TO REDUCE ANXIETY AND INCREASE SAFETY OF NEONATAL INTUBATIONS)}

N Audhali, I Gregory, G Nair, R Singh, J Oleksiewicz, P Kalaivanan. Paediatric Department, Whipps Cross Hospital, London, UK

\subsection{6/archdischild-2020-rcpch.87}

Aim Intubation on a DGH Neonatal Unit can be risky and stressful for a new registrar. We know that intubations in non-specialist centres have greater risk of adverse events, and evidence for use of safety checklists, is well established. We aimed to improve safety and staff confidence in delivery of care on our neonatal unit by launching a safety checklist for this and other invasive procedures. This would function as an aide memoire for the performing clinician, support good team-working, empower assistants to help and to raise concerns when appropriate.

Methods Taking a quality improvement approach, we set up a team of doctor and nurse champions to develop, pilot and embed our safety checklist. We started with a preliminary staff survey of doctors and nurses via survey monkey and paper questionnaires. We developed checklists for intubation, central line, long line, lumbar puncture and chest drain using NHS England's template. These were made widely available and launched via staff seminars, handover bulletins, and posters. At 3 months post-launch we carried out a Quality Peer Review to assess staff response to the checklists. Audit data for intubation, and central, and long lines were collected at 6 months to review quantitative take up of the checklists.

Results Preliminary survey responses: 19 respondents, most $(n=15)$, thought intubations safe but some $(n=4)$ thought they were only somewhat safe or not safe. All respondents $(n=19)$ thought checklists would make intubation on the unit safer, and most, $(n=18)$ thought they would make documentation easier. 24 hour Peer Quality review data: themes reflected staff perception's that checklists improved team working, reduced stress, and increased safety of invasive procedures. Our preliminary 6-month audit data showed: 15 intubations of which most $(n=13)$ had checklists correctly used, 24 central and long lines of which most $(n=22)$ had checklists. We will continue to collect and analyse data for the next year. Checklist use has been adopted into departmental induction this September. 
Conclusion Safety checklists were a popular intervention and had good uptake when launched on our unit. They have improved staff confidence during intubations, supporting safer care, good documentation, and education and training.

\section{G111(P) HAVE WE HIT THE MARK? BOOSTING CONFIDENCE TO IMPROVE OUTCOMES IN STRESSFUL SITUATIONS}

${ }^{1} \mathrm{~L}$ Rehman, ${ }^{2} \mathrm{M}$ Kamal, ${ }^{1} \mathrm{P}$ Cahill, ${ }^{3} \mathrm{M}$ Hussain, ${ }^{1} \mathrm{M}$ Shahid. 'Paediatrics Department, Portiuncula University Hospital, Ballinasloe, Ireland; ${ }^{2}$ Paediatric Emergency Department, Tallaght University Hospital, Dublin, Ireland; ${ }^{3}$ Department of Children and Young People, North Cumbria Integrated Care, Cockermouth, UK

\subsection{6/archdischild-2020-rcpch.88}

Aim

- To analyse whether initial consultant-led simulation-basedteaching-sessions (SBTS) boost junior doctors participation levels' as team leaders.

- To determine the influence of SBTS on non-clinical hospital doctors (NCHDs) baseline knowledge, confidence, comfort levels and situational awareness in stressful Paediatric/ Neonatal situations.

Method A two-part survey was designed and distributed at the start of the rotation in a formal setting of 'SAFE' (Situational Awareness For Everyone) by lead consultant. ${ }^{1}$ The first part included a comprehensive questionnaire outlining Paediatric BLS, ALS and Neonatal resuscitation to assess the baseline knowledge of all NCHDs. The second part helped us establish NCHDs experience, confidence and comfort levels when participating in SBTS sessions. ${ }^{1} 2$ Initial three months: Neonatal and Paediatric team leaders were designated among consultants to plan/coordinate among all NCHDs. A schedule of weekly Paediatric/Neonatal scenarios was distributed. Second three months: Team members volunteered to lead random scenarios per week. Overtime, situational awareness of team members was also assessed. ${ }^{1}$ After six months, the same survey was redistributed.

Results NCHDS' were categorised according to their level of experience in Paediatrics. NCHDs' who had between 0-1 years' experience in Paediatrics were not very confident and not very comfortable as team leaders and scored on average $63 \%$ on the baseline knowledge questionnaire. Post intervention most NCHDs had become very confident and very comfortable dealing with stressful situations and better retained baseline knowledge, scoring an average of 92\%. NCHD's who had $3+$ years' experience were confident and comfortable to begin with and those levels only improved over six months. ${ }^{1}$ 2 Baseline knowledge was maintained, further refining from $81-96 \%$.

Conclusion Our main cohort of junior doctors is GP trainees who rotate from different specialities every six months with none - minimal Paediatric/Neonatal exposure and knowledge as evident from the above results. Initially they were reluctant to participate due to the fear of being judged. However, our consultant-led strategy boosted their knowledge, confidence and comfort levels as well as situational awareness to lead and deliver better patient care in stressful situations.

\section{REFERENCES}

1. Rakshasbhuvankar, Abhijeet \& Patole, Sanjay. (2014). Benefits of simulation based training for neonatal resuscitation education: A systematic review. Resuscitation. 85. 10.1016/i.resuscitation.2014.07.005.
2. Schweich PJ, DeAngelis C, Duggan AK. Preparedness of practicing pediatricians to manage emergencies. Pediatrics 1991;88:223.

\section{G112(P) ARE WE FACING THE FUTURE? A REVIEW OF ACUTE GENERAL PAEDIATRIC ADMISSIONS AT A REGIONAL PAEDIATRIC HOSPITAL}

T Kendrew-Jones, S Farquharson, E Stewart, O Forbes, R Bland, L Nairn. General Paediatrics, Royal Hospital for Children, Glasgow, UK

\subsection{6/archdischild-2020-rcpch.89}

Aims To assess whether the Royal College of Paediatrics and Child Health 'Facing the Future: Standards for acute general paediatric services' (2015) are being achieved and if changes to service have improved performance.

Method Between May and August 2018 there was a phased reconfiguration of services, with merging of two inpatient units and redesign of middle grade and consultant rotas at our tertiary paediatric hospital $(68,000$ unscheduled care attendances per annum). This redesign has ensured compliance with Standards 1,4 and 6-10. We performed a retrospective case note review of admissions in May and September 2018 to assess performance against Standards 2, 3 and 5. A list of all acute general paediatric admissions was obtained and electronic patient records for every patient admitted on 12 preselected days each month were reviewed to document when children were first reviewed by senior clinicians (tier 2 doctors and consultants).

Results 219/265(82.6\%) patients were reviewed by a tier 2 doctor or above in May 2018 and 244/284(85.9\%) in September 2018 (table 1). Review within 4 hours occurred in $124 / 265(46.8 \%)$ in May and 159/284(56\%) in September. Most patients admitted over 14 hours had a consultant review during admission (87.9\% in May and $79.3 \%$ in September); however, this review was often out with 14 hours.

\begin{tabular}{|c|c|c|c|}
\hline & RCPCH & May-18 & Sept-18 \\
\hline & Standard & & \\
\hline General paediatric admissions ( $\mathrm{n}$ ) & & 784 & 744 \\
\hline Cases reviewed (n) & & 265 & 284 \\
\hline Tier 2 or above review during admission $(n ; \%)$ & & $219(82.6 \%)$ & $244(85.9 \%)$ \\
\hline Tier 2 or above review $\leq 4$ hrs $(n ; \%)$ & 2 & $124(46.8 \%)$ & $159(56 \%)$ \\
\hline $\begin{array}{l}\text { Seen or discussed with Tier } 2 \text { or above before } \\
\text { discharge }(n ; \%)\end{array}$ & 5 & $232(87.5 \%)$ & $258(90.8 \%)$ \\
\hline Patients admitted $>14$ hrs (n) & & 116 & 116 \\
\hline Consultant review during admission $(n ; \%)$ & & $102(87.9 \%)$ & $92(79.3 \%)$ \\
\hline Consultant review $\leq 14$ hrs $(n ; \%)$ & 3 & $33(28.4 \%)$ & $35(30.2 \%)$ \\
\hline
\end{tabular}

Conclusion Facing the Future Standards were considered during the design of acute paediatric services. We achieve seven of ten standards, with senior clinician review of most children during admission. However, with a large volume of unscheduled care attendances, early review remains the biggest challenge. Subsequent changes to our service have included expansion of consultant workforce and relocation of senior clinicians to the Emergency Department. 2019 data are collected and being analysed for comparison. 